This item was submitted to Loughborough's Research Repository by the author.

Items in Figshare are protected by copyright, with all rights reserved, unless otherwise indicated.

\title{
Learn to write badly: how to succeed in the social sciences
}

PLEASE CITE THE PUBLISHED VERSION

PUBLISHER

Cambridge University Press @ (c) Michael Billig

VERSION

AM (Accepted Manuscript)

LICENCE

CC BY-NC-ND 4.0

REPOSITORY RECORD

Billig, Michael. 2019. "Learn to Write Badly: How to Succeed in the Social Sciences". figshare. https://hdl.handle.net/2134/15319. 
This item was submitted to Loughborough's Institutional Repository (https://dspace.lboro.ac.uk/) by the author and is made available under the following Creative Commons Licence conditions.

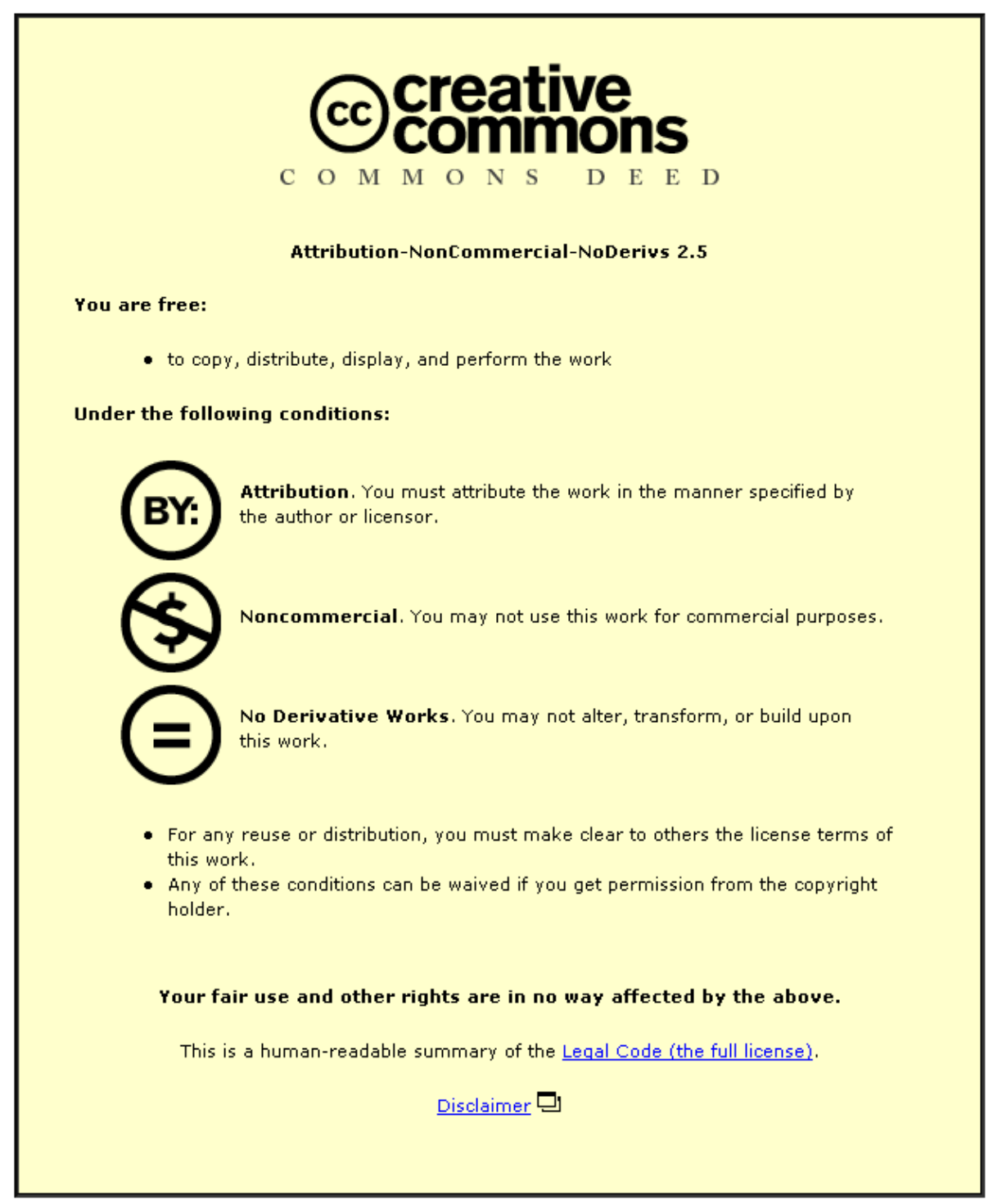

For the full text of this licence, please go to: http://creativecommons.org/licenses/by-nc-nd/2.5/ 
Learn to Write Badly:

How to Succeed in the Social Sciences

\author{
Michael Billig \\ Department of Social Sciences
}

Loughborough University

To be published by Cambridge University Press, 2013 
Chapter One

Introduction

This is a book which complains about poor writing in the social sciences. The author is not someone who is offering criticisms as an outsider looking in upon a strange world. I am an insider, a social scientist, and I am publically criticising my fellows for their ways of writing. Anyone, who does this, can expect to have their motives questioned. Readers may wonder whether the author is embittered, having seen younger colleagues overtake him in the race for academic honours. Perhaps he has been slighted in the past by senior figures and now he is determined upon gaining his revenge. Or possibly the author is deeply flawed as a person, a serial trouble-maker, who is constantly picking quarrels and seeking to be centre of attention.

So, I should begin with a few personal remarks. I am not a young scholar, rebelling against the establishment, but I am approaching the end of my working life, having spent almost forty years in continuous employment as a university teacher. It has, for the most part, been a wonderful job. Not only has the work been relatively well remunerated, but it has been a privilege to be paid for reading and writing; and it has not been a hardship to teach bright, young people, some of whom have even been interested in the topics that I have taught. I cannot imagine a better way to earn a salary; but that may say more about my lack of imagination than it does about working as a modern academic in the social sciences.

Doing the job has not always been easy or free from insecurities. There are some academics that one cannot envisage in any other line of work - they seem to belong so perfectly to the world of scholarship that they would be misfits in the so-called 'real' world. Some of my 
colleagues and students might think that of me. It would be nice if they did, but I should say that for me it has not felt that way at all - and this is relevant to my reasons for writing this book.

When I was a student of philosophy and psychology at Bristol University in the late 1960s, it did not occur to me that I would ever stay at university after I had finished my undergraduate degree. I was doubly fortunate that Henri Tajfel, one of the greatest social psychologists in the discipline, was my teacher, and that he persuaded me to consider doing a doctorate under his supervision. Without that encouragement, my life would have been considerably different. As a doctoral student, however, I never felt that I properly belonged to the world I was entering. My big problem was that I could not master the academic language which I was expected to use. I would struggle to read articles and books with complex, technical terminology. I would try to translate the unfamiliar words into simpler ones, into the ordinary language that I used in daily life. Sometimes, I succeeded in doing so, and sometimes I didn't. And occasionally, when I'd finished the translation, the ideas and the sense seemed to dribble away, leaving truisms and little else. Then, I would be perplexed. Was it my failure to understand or was it that a writer, who had actually been published, really had so little to say? I could hardly believe the latter possibility.

I would look with envy at my fellow postgraduates who could use the terminology easily and who did not seem to suffer from my problems. Not only could they speak fluently in this strange, unfamiliar language, but they could even think in it. And that I most certainly could not do and I still don't know why. All I know is that I never got past the stage of translating the big words into smaller words: I never became a fluent speaker, let alone a thinker, of the academic dialect. Even after I obtained a post in the psychology department at Birmingham 
University, things did not become easier: I still could not use or understand the words that a young social psychologist should use. After a while, I stopped reading the journals that I ought to have been reading. The superb library at Birmingham had so much else to offer. I still remember the first time I read Hannah Arendt's Eichmann in Jerusalem, and feeling so utterly changed. Few books have affected me as deeply and shown me how little I knew. Or, on a more pleasurable level, I remember reading C.L.R. James’s Beyond a Boundary. Later I would have similar feelings of delight when reading Freud, although I was always aware that he could simultaneously be wise and silly.

Despite their intellectual differences, Arendt, James and Freud share one thing in common: none was a professional academic, writing primarily for other academics. The academic terminology, which I could not master or take into myself as my own, seemed paltry by comparison to their words. George Orwell's wonderful essay 'Politics and the English Language' helped put things into perspective. I felt heartened: perhaps the fault wasn’t mine but some academic social scientists, by using long words, were dressing banalities up as profundities. Maybe - and this was too liberating to say out loud - my strategy of translating academic words might not be a sign of shameful inadequacy, which I dare not admit to others, but possibly I had stumbled unwittingly upon a strategy which would protect me. After all, I did not need to translate Arendt or James or Freud: study, re-read, struggle to understand, yes, often; but translate into simple words, never.

So, it has continued over the years. I have avoided reading the technical journals which I should read and which I occasionally publish in. I have never taken on the technical terminology as if it were my first language. I still have to translate if I wish to understand the academic articles that I do read. But I no longer feel ashamed. Today, I can see young 
postgraduates struggling to understand what they know they must read. Sometimes, I see their confidence draining away in the face of big words, as if they were failing the test that defines whether they are fit to think intellectually. I want to tell them to trust their own supposed inadequacies, for their failings might protect them from the onslaught of big words. I hope that some young academics, who are today as uncertain as I was years ago, may take some confidence from this book.

\section{The nature of this book}

This is by no means the first book to criticise the use of academic jargon either generally or more specifically in the social sciences. Just over forty years ago, Stanislav Andreski (1971) caused a stir with his Social Sciences as Sorcery, a book which took social scientists to task for their inability to write clearly. In his ferocious onslaught, Andreski claimed that intellectual standards were declining: compared with half a century ago, there was, he suggested, an 'abundance of pompous bluff and paucity of new ideas' (p. 11), and that this was another reflection of modern society’s ‘advanced stage of cretinization’ (p. 17). It was gloriously ill-tempered stuff but very much the voice of an embittered person.

Much gentler was Brand Blanshard’s On Philosophical Style (1954), a delightful little book in which the distinguished American philosopher argued that philosophers should try to write as clearly as possible and that it was bad manners not to try to do so. More recently, we have had the physicist Alan Sokal castigating post-modernist theorists, both literary and social scientific, for writing in a wilfully obscure manner (Sokal and Bricmont, 1999; Sokal, 2010). When Sokal revealed that he had successfully submitted a spoof article to a post-modernist journal, which had published it in all seriousness, a public brouhaha ensued with much anger and accusation on both sides. 
I hope that my book will differ from these earlier works in a number of respects. Unlike Sokal, I am not attacking a particular viewpoint in the social sciences. I am not implying that if we could only get rid of continental philosophy and its adherents, all literary wrongs would be put to rights. In fact, I will hardly be mentioning post-modernist theorising at all, not because I find the literary styles of Derrida, Lacan, Deleuze and their followers, commendable for the social sciences but because they are not the issue. Even if we lanced the Lacanian boil, as Sokal would wish, the patient would still be suffering from a serious rhetorical sickness.

Besides, I have criticised Lacan and his style of writing elsewhere and there is no reason to repeat those criticisms here (Billig, 2006). Lacan famously considered his work to be a return to Freud, but rhetorically this could not have been further from the case. Lacan was an obscure writer, who seemed to delight in making things difficult to grasp, offering few examples to illustrate his allusive points. Freud could be a wonderfully clear writer, who tried to draw his readers in with beautiful metaphors, jokes and, above all, clear examples. As I will suggest later in Chapter Five, Freud could also write in a pseudo-scientific style, much to the detriment of his theory. Brand Blanshard has a lovely remark that is apposite, in my view, to Lacan and others like him: 'Persistently obscure writers will usually be found to be defective human beings' (1954, pp. 52-3). Blanshard was saying that authors, by their style of writing, are showing how they treat their readers and, thereby, how they treat other people. The persistently obscure writer can be like a bully, who tries to humiliate others into submission. Personally, as a reader, I would rather be charmed, even seduced, by a Freud than bullied by a Lacan. 
My criticisms, however, are much wider than criticising the style of an individual author or of a particular school of social scientists. In this respect, my book is closer to Andreski's onslaught than to Sokal's. Andreski was criticising the mainstream social scientists of his day, rather than a comparatively small group of exotic radicals. Principally, he was gunning for respected figures like Talcott Parsons, Robert Merton and Robert Linton. He was not suggesting that they were defective human beings, although he was not so kind about their followers. Regarding Talcott Parsons, Andreski wrote that 'the Grand Master' was an honourable man, who, like all 'effective sorcerers', sincerely believed in what he was saying and who 'takes no part in the intrigues and machinations rampant among the academic jet-set, and for that reason he has been cold-shouldered by the common run of manipulators since his retirement, despite his great fame’ (1971, p. 162).

Andreski could certainly turn out a good sentence, but I hope that my tone differs from his. The real difference between my critique and his - and also between my critique and those of Blanshard and Sokal - is neither tone nor target, but in analysis. Andreski’s book, it must be said, is stronger on rant than analysis. Blanshard's arguments about the need for authors to use concrete examples to illustrate theoretical points are still valid and sociological theorists today could do far worse than read his largely forgotten book. However, Blanshard does not discuss the pressures of modern academic life that may lead to hasty writing; nor does he analyse precisely what may be amiss in current styles of academic writing. Although Blanshard cites William James approvingly - quoting Whitehead's praise of 'that adorable philosopher' (Blanshard, p. 17) - he does not mention that James criticised the academic system of his day, suggesting that it was encouraging young academics to write poorly. Later, I will be referring to William James and his critique of the division of the academic world into different disciplinary territories. His observations are still pertinent for understanding the 
relations between academic life and academic writing and, of course, they are wonderfully written.

My analysis will have two threads: the first is to examine the conditions under which academic social scientists are working; and the second thread is to examine the linguistic nature of what we produce as writers of the social sciences. I will be suggesting that the two threads are connected. The first part of the argument will be familiar to anyone working in higher education today: academics work in an increasingly commercial culture, as universities, disciplines and individuals compete economically. In this competitive culture, it has become second nature to promote oneself and one's work.

The second part of the argument may not make for comfortable reading: this culture of competition and self-promotion is seeping into the content of our academic writings. This is a culture in which success and boasting seem to go hand in hand. When we write, we are constantly boasting about our approaches, our concepts, our theories, our ways of doing social sciences and what these products can achieve. It is boast after boast, but we scarcely notice that we are writing like academic advertisers and that we are training our students to do likewise. And we boast of our big words which have become part of the product portfolios that we promote.

In the following chapter, I will begin analysing the conditions under which modern social scientists work. There has been a massive expansion of higher education and in the production of research, such that academics are expected to publish continuously and voluminously. There is so much publishing going on that the academic world is inevitably divided into smaller and smaller circles. In order to keep up with the pressures of work in an 
increasingly competitive world, academics are producing hastily written works. As the old saying goes, easy writing makes hard reading. William James once said that if there was anything good in his own style of writing, then it was 'the result of ceaseless toil in rewriting' (quoted in Richardson, 2007, p. 298). Such toil in rewriting is not possible when academics have to publish ceaselessly. It is not merely the style that suffers, but so does the content. When writing for audiences of specialists, it is easier and certainly speedier to reach for the common technical terminology than to try to clarify one's thoughts. Hence big words are circulating in decreasingly narrow circles.

In Chapter Three, I will be looking at the way that young social scientists enter the academic world - how they progress from being undergraduate students to being fully fledged members of the trade. Because social scientific disciplines are so diverse today, the young apprentice academic has to do more than become a 'sociologist' or an 'anthropologist' or a 'psychologist'. Typically, they have to associate themselves with a specific approach, a theoretical perspective or an already existing body of work. To do this, they have to accept the technical terminology of their chosen world, as well as the assumption that this technical terminology is superior to ordinary language. And then they are expected to promote their own work, their approach and the language of their approach.

As I look at what is happening in the social sciences in these chapters, I will be citing studies which social scientists have produced about current university life, its commercial culture and the ways that postgraduates become professional academics. These studies are important for what they contribute to our knowledge about universities, but I will also be using them as examples of the ways that social scientists use language. I want to avoid going out of my way 
to look for imprecise, over-technical writing, for then I could be accused of selecting extreme examples just to fit my case. Instead, I will be using examples where I find them.

I will continue this strategy in the subsequent three chapters (Chapters Four to Six) as I look at the linguistic features of contemporary academic writing. Those who examine current trends of writing will at times become my examples of those trends. In the first of these three chapters, I will be discussing the reasons that social scientists sometimes give for using technical terminology. They claim, for instance, that ordinary language is too imprecise or that it is too infected by the philosophy of common sense. However, the defenders of technical jargon seem to overlook that academic terminology is heavily weighted towards nouns and noun phrases, with verbs, by comparison, hardly getting a look in. For me, that characteristic of contemporary academic writing is highly significant.

In the following two chapters, I develop the linguistic themes that I have introduced in Chapter Four. Basically, I consider why a noun-based style of writing, which is entirely appropriate for the natural sciences, is inappropriate for the social sciences. Although current styles of writing can be awkward and unlovely, my argument is not primarily aesthetic. The trouble is that when we use noun-based styles in the social sciences, we run the risk of rhetorically turning people into things - of reifying people. Significantly, sociological theorists, such as Peter Berger, who have looked at this topic, tend to use the noun 'reification' rather than the verb 'to reify'. When theorists write in this way, they treat the problem as a thing, and thereby, even as they warn against the dangers of 'reification', so they contribute to the problem. 
Here, then, is the centre of my argument: the big concepts which many social scientists are using - the ifications and the izations - are poorly equipped for describing what people do. By rolling out the big nouns, social scientists can avoid describing people and their actions. They can then write in highly unpopulated ways, creating fictional worlds in which their theoretical things, rather than actual people, appear as the major actors. The problem is that, as linguists have shown, using nouns and passive sentences is a way to convey less, not more, information about human actions.

The paradox is that both bureaucrats and natural scientists use heavily nouny styles, often because they can avoid specifying who is doing what. In my view, it has been disastrous for social scientists to follow them. I will be giving examples from critical linguists, who show how bureaucrats and ideologists use particular linguistic constructions, such as 'nominalization' and 'passivization', to avoid specifying who does what in the world. But, just as sociologists prefer to write of 'reification', rather than people 'reifying', so linguists talk of 'nominalization' not people ‘nominalizing' and, in doing so, they produce examples of the problem that they are critically examining. At root, there is a problem in preferring the big technical noun to the shorter, humbler verb.

In Chapters Seven and Eight, I finally depart from the strategy of taking my examples where I find them. Instead I present some case studies of current rhetorical trends in sociology and experimental social psychology. In Chapter Seven, I look at sociological writings, with my case studies initially coming from three articles, which the editors of a major sociological journal have singled out as representing work of particular importance. Then I look at a way of doing sociology - conversation analysis - which seems to be the antithesis of those other three pieces of work. 
In Chapter Eight, I analyse the rhetorical practices of experimental social psychologists. Perhaps, more than any social scientists, experimental social psychologists try to write as natural scientists do. The end result is not that experimental social psychologists write precisely, but that they routinely exaggerate their results and conceal aspects of what occurred in their experiments. In common with other social scientists, they use their big, nouny concepts incredibly loosely.

In my final chapter, I make some recommendations about how to reverse these patterns of loose, imprecise writing. Having identified the linguistic basis of the problem, it is not difficult to make recommendations: basically the recommendations point to the importance of using ordinary terms where possible and using verbs in the active voice rather than nouns which theorists have formed from verbs. Making recommendations is the easy part, but I have few expectations that they will have any effect. The conditions of academic life, which I analysed in the earlier chapters, will persist and so long as they do, we cannot expect great changes in the ways that social scientists write.

I cannot imagine how my book could possibly change these conditions. A few readers may take heart from what I say; a handful might even try to change how they write; many more readers will find reasons to disagree with me, especially in relation to their favourite big words. The vast majority of social scientists, however, will not read this work, or even know of its existence, and they will carry on as they are.

\section{$\underline{\text { Some caveats }}$}


Having remarked on the book's contents, I should now offer some caveats about what is not in the book. I write loosely about 'social scientists', and, in consequence, readers might expect me to analyse all the social sciences. However, I will only be examining a very circumscribed set of social scientists. It is part of my argument that the social sciences have expanded so rapidly and individual disciplines have become so diversified, that no individual academic can keep up-to-date with developments within their own discipline, let alone neighbouring disciplines. When Andreski was making his criticisms, sociology was a much more unified discipline, and everyone could recognize who were the senior figures. Now there are diverse sociological approaches, each with their own set of major figures. In the current chaos of social scientific disciplines, we can all be somewhat egocentric, imagining our particular interests to be central, while other approaches are marginal. So, inevitably some readers will take exception to my choice of examples, complaining that I have not discussed the really important approaches. I will return to this in my concluding chapter. However, if I use the terms ‘social sciences’ and ‘social scientists’ more generally than I should, then I apologise in advance.

A second caveat is that I am not arguing that social scientists should be public intellectuals. It is true that I am arguing that social scientists should write more simply, and it is true that those social scientists who wish to address the public also need to write simply. And, as Michael Burawoy has argued, there are good reasons why social scientists should seek to address the wider public (e.g., Burawoy, 2005). Because I suggest that academics should write more simply, this does not mean that I am arguing that they should be addressing the general public. Most public intellectuals are bi-lingual: they use one language for addressing the public and another for addressing fellow specialists. I am suggesting that we address our fellow specialists more simply, whether or not we seek to address the general public. It would 
be strange were I arguing that we all need to be public intellectuals in a book, which is itself aimed at academics rather than at a wider audience. I will not be rushing to the television studios to tell viewers: 'Did you know that some linguists write about nominalization without telling us who is nominalizing? Isn’t that shocking? Aren’t you appalled?'

Although I will be writing in general terms about social scientists writing badly, this will be misleading. In consequence, another advance apology is in order for all the occasions when I imply that all social scientists are poor writers. So, here is another caveat: there are exceptions, but for the most part I will be overlooking the exceptional writers in the social sciences. I will not be trumpeting the stylistic merits of an Erving Goffman or a Richard Sennett or a Deborah Tannen and then saying 'We should all try to be Goffmans, Sennetts and Tannens'. Largely, it would be useless to say this. Notably good writers in the social sciences, as elsewhere, are notable because they have their individual voices which others cannot properly copy. Sadly it is easier to copy really poor writers, than really good ones. Accordingly, I am hoping to identify faults in the writings of workaday social scientists in order to say 'We should be trying to avoid these faults'. For the rest of us, who are not Goffmans, Tannens or Sennetts, this is a more manageable, more realistic message. It is certainly more manageable for the large number of academics, whose native language is not English but who find themselves being pressured to publish in English. They have a hard enough job to write clearly in a second or third language without having to aspire to write with aesthetic elegance in that language.

My last caveat is that I am not wishing to obstruct innovation, whether academic or linguistic, nor am I defending the use of old-fashioned English. I have mentioned Orwell's 'Politics and the Use of English' as an inspiration, but Orwell's essay has a weak spot. At one point, 
Orwell recommends authors to choose English words of Anglo-Saxon origin over those with Latin roots. I can understand why Orwell made this recommendation, but it is no part of my argument. When I criticise the use of 'reification', I do not suggest that it would have been better had social scientists used 'thingification'. From my point of view, the problem lies in the suffix - 'ification' - rather than in the etymology of the first part of the word. All my arguments about the use of 'reification' would apply equally to the word 'thingification'.

What I do contest, however, is the assumption that, in order to have original thoughts, you must inevitably create new nouns - or, correspondingly, if you create new words, you are being original. Those assumptions are historically unjustified, for in the past there have been outstandingly original thinkers who have used existing words. Plato's dialogues - and most particularly the character of Socrates - are obvious examples. In the seventeenth century, John Locke rejected the scholastic jargon of philosophers like Ralph Cudworth and wrote clearly and originally using the ordinary language of the day. Also, there are two writers, whom I have already mentioned - William James and his namesake C.L.R. There is another thinker whom I have not mentioned: Ludwig Wittgenstein, who not only transformed views about language, but never used a technical term to do so. His work shows that it is possible to use ordinary language originally, even using it to show how we ordinarily use ordinary language. Although I do not mention Wittgenstein again in this book, his influence runs throughout.

The example of Wittgenstein suggests that big, technical words can restrict, rather than aid, our understanding. This is especially so in current times when self-declared experts can commercially market big new words as big new ideas. Academics, too, often act as if we cannot have a new approach, theory or insight, unless we have a new noun to promote. We 
should not automatically think that this way of writing is radical. As social scientists, we might feel that we must stand outside current, commercial trends if we are to understand the world, in which we live; if so, that is all the more reason why we should try to use fewer, not more, specially manufactured, competitively promoted big nouns.

Lastly I should add a brief word about the book’s title. Learn to Write Badly: how to succeed in the social sciences is not the type of title that one would expect for a serious, academic book. Quite apart from anything else, its ratio of nouns to other parts of speech is low - the one solitary noun is even outnumbered by verbs. This is not accidental, for grammatically the title matches my underlying argument. It also parodies the titles of those 'how to succeed' books that are so popular nowadays. But this expresses an underlying dilemma. By exploring the nature of academic writing and by taking apart some of its constituent features, I am inevitably running the risk of providing a manual, which instructs readers how to write in the very style which I am criticising. I can see no way around this dilemma, except by parody. Nevertheless, even the parody has a serious point. The bad writing, which I am writing about, has not been produced by too little education. Quite the contrary, you have to study long and hard to write this badly. That is the problem. 